\title{
Environmental awareness
}

\section{A competing motivation}

\author{
Although environmental awareness is a strong \\ motivation, even for highly engaged individuals \\ it has to compete with other motivations in \\ guiding behaviour. A process-oriented approach \\ to this dilemma allows for alternative behaviour \\ and continuous engagement. That approach \\ might be transferred also to organizational units. \\ By Ines Thronicker
}

\section{Problem and research question}

The discordance of or 'gap' between individual pro-environmental values, attitudes, or intentions and the respective behaviour is well documented for a variety of behavioural domains. However, the identification of the phenomenon's roots is still a matter of research. Supposed causes of this gap address all parts of the chain, i.e. (a) the beliefs, for example lacking moral norm or environmental awareness (Carrington et al. 2010; Gaston et al. 2005), or high materialistic values (Hurst et al. 2013), (b) the respective behaviour, for example high behavioural costs including strong habits (Kaiser et al. 2010; Johnstone/Tan 2015; Chai et al. 2015), and (c) the link from belief to behaviour, for example low self-efficacy expectation or perceived behavioural control (Bamberg/Möser 2007; Rabinovich/Webley 2007), strong social influence via group norms, identity and status (O'Rourke/Lollo 2015), or biased perceptions of own impact (Entzian 2016). Also methodological biases are discussed (Carrington et al. 2010). However, although motivations, i.e. active orientations towards a specific behavioural outcome, are strongly influential on behaviour, they are only indirectly and unsystematically considered in their potential to contribute to the observed gap. In addition, the handling of the gap ought to be of societal interest, too, since it provides orientation on how to go on with the endeavours of sufficiency and societal transformation despite the empiric behavioural gap. Studies mainly focus on the general public, possibly based on considerations of the effects of accumulated individual behaviour. However, the general public only tells us how on average behavioural gaps evolve and how on average they are dealt with, thus reveal some kind of mainstream problem solving. However, it seems valuable to focus on possible experts in this regard: We wondered whether, and how people that are highly committed to environmental concerns experience behavioural gaps, and how they deal with it.

\section{Method and Sample}

The EU FP7-funded project GLAMURS focused on the lifestyles of people engaged in sustainability related communitybased initiatives in seven European case studies: organic agriculture as well as climate and energy model region (Austria), Transition Town Movement (Germany), agricultural cooperatives (Italy), ecovillages (Romania), tempo-spatially flexible working programme (Scotland), cooperatives of consumers and local NGOs (Spain), repair cafés and energy cooperative (The Netherlands). Among a variety of methods applied during the project, we conducted qualitative in-depth interviews to explore the participants' view on a range of issues related to a sustainable lifestyle. The research teams of the case studies jointly developed the empirical interview approach including agreements on shared procedures and materials for sampling, interview guidelines, coding framework, coding, data analysis, and data interpretation. In each case study between 13 and 18 qualitative in-depth interviews were conducted $\left(\mathrm{N}_{\text {total }}=105\right)$, mainly with members of the initiatives, but also some with interested participants not engaged in the initiatives. The sample consisted of 45 female and 60 male participants, ranging from 19 to 72 years in age. About half of the interviewees had children.

The interviews referred to potential behaviour gaps by the question, whether the interviewee ever experienced situations in which they knew what would be the appropriate sustainable behaviour and in which they were able to conduct it, but still decided for a less sustainable behaviour or choice. During each interview, we went on using the terms the interviewees came up with to describe such situations, e. g. "feel torn", to ask about related cognitions, emotions, and behaviour in this very situation and thereafter.

\section{Results and Interpretation}

Situations that yield a behavioural gap, i. e. behaving not in line with one's environmental attitude although feasible, were familiar to nearly all interviewees. But, against our expectations they were hardly experienced as conflicts. In the interviews as well as the analysis, we concentrated on how the interviewees described the emergence of the gap and how they then dealt with the situation.

All participants reported that these situations offered various behavioural options which served strong but competing motivations, respectively. On the one hand, felt responsibility for the environment, preservation of a consistent self-image, or 


\section{„Environmental awareness \\ is in competition \\ with other motivations."}

strong altruistic/transcendent values oriented the interviewees towards the more sustainable behaviour. On the other hand, interviewees were often oriented towards the less sustainable behaviour (a) by smaller individual costs and higher personal comfort, e. g. in terms of temporal or financial effort, (b) by the relevance of social relations, such as identity, belonging, status, (c) by felt responsibilities and obligations, such as family duties. Whatever behavioural option participants decided for, it always was a more or less clear prioritization of one motivation over the other. This implies two aspects. Firstly, it is not that interviewees felt hindered to conduct the sustainable behaviour, but consciously decided against it. Secondly, it shows that environmental or sustainability awareness is one motivation among others that compete for influence, thus its influential power on behaviour has to be considered in relation to other motivations.

We identified two approaches to deal with these torn-between situations. One approach is characterized by strategies that aim at reducing the motivational power of sustainability or environmental awareness, e. g. by relativization, justification, social downward comparison etc.

"We will go on holidays soon. Then we do go by airplane. That is not really sustainable [...]. But yes, on the other hand: We don't drive a car, so that makes it right again, so to say." (The Netherlands, male)

- "I mean, what do other people fly around?! So I am free to that also once." (Germany, female)

- "I'll bet my carbon footprint is hugely less than most people." (Scotland, male)

These strategies aim at clarifying the situation in a way that prevents the dilemma of competing motivations in comparable future situations. Such strategies are found in studies with the general public, where they are described as coping strategies to deal with the injunctive norm to behave pro-environmentally (Stich und Wagner 2012, Homburg et al. 2007). This 'closure' approach can well be understood by the theory of cognitive dissonance (Festinger 1957). In the situations described by our interviewees, the 'closure' approach nearly always went along with the choice of the less sustainable behaviour. Note that no causal inference can be drawn.

The other approach differs in that the torn-between situation is conceived as an experience within a process of learning and that the competition of motivations is a permanent negotiation process (Bamberg/Möser 2007; Lavergne/Pelletier 2015). This 'process' approach aims at clarifying the situation in a way that improves the negotiation of comparable dilemmas in the future. It entails:

1 a reflection of the underlying motivations ("It's not just external pressure, it's also my own values in relation in wanting to keep friendships alive." Scotland, male)

- the acceptance of motivational dilemmas as such ("Whether this bothers me? I say yes to the situation! That's the first." Germany, female)

- the acceptance of the variability of motivational forces over situations and time ("You cannot refuse to have a nice gathering with your friends in front of a good grilled meat." Italy, female)

- the readiness to try new behaviours ("What happens is that after all this toying around, you discover that in fact you can do things that seemed very far away from you." Romania, male)

- and often an active search for creative solutions ("Stress arises when you do not reconfigure your life." Spain, male)

Vitally, the behaviour conducted in the very situation is not perceived as a definite solution to the dilemma, but as a try within a process, at best a step towards a goal. Therefore, the 'process' approach might best be understood by theories on learning and complex problem solving.

\section{Conclusion and Outlook}

Given our sample of highly interested or engaged individuals, not surprisingly we found that environmental and sustainability awareness clearly was a strong motivation. At the same time, this motivation did not stand alone to guide behaviour but had to compete with other motivations. Environmental and sustainability awareness can be perceived as a threat to other motivations, then dissonance theory possibly applies, or as a catalyst for creative solutions, then theories on complex problem solving supposedly best apply. Obviously, the individual perception and interpretation of the dilemma influences how the individual deals with it. For a start, research would do well leaving the tunnel view on environmental awareness but consider it among and in competition with other motivations. Further, motivational and consequently behavioural dilemmas have to be understood and treated as a process, firstly because a 'closure' approach will reach its limits with rising pressure of environmental challenges, secondly because it facilitates urgently needed creative and new solutions. Research reasonably should focus on what influences the negotiation process across situations and over times, including the consideration of possible moderators, e. g. norms, resources, freedom, or mediators, e.g. autonomy or self-efficacy. Finally, it seems worthwhile to examine how the characteristics of an individual 'process' approach could be transferred to the community, society, business, or other organizational units that all are challenged with comparable environmentally related motivational dilemmas. 


\section{References}

Bamberg, S./Möser, G. (2007): Twenty years after Hines, Hungerford, and Tomera: A new meta-analysis of psycho-social determinants of pro-environmental behaviour. In: Journal of Environmental Psychology 27/1:14-25.

Carrington, M. J./Neville, B. A./Whitwell, G. J. (2010): Why Ethical Consumers Don't Walk Their Talk: Towards a Framework for Understanding the Gap Between the Ethical Purchase Intentions and Actual Buying Behaviour of Ethically Minded Consumers. In: Journal of Business Ethics 97/1: 139-158.

Chai, A./Bradley, G./Lo, A./Reser, J. (2015): What time to adapt? The role of discretionary time in sustaining the climate change value - action gap. In: Ecological Economics 116: 95-107.

Entzian, A. (2016): Denn sie tun nicht, was sie wissen. Eine Studie zu ökologischem Bewusstsein und Handeln. München.

Festinger, L. (1957): A theory of cognitive dissonance. Stanford, CA

Gaston, G./Connor, M./Sheeran, P. (2005): Bridging the intention - behaviour gap: The role of moral norm. In: British Journal of Social Psychology 44/4: 2044-8309.

Homburg, A./Stolberg, A./Wagner, U. (2007): Coping with global environmental problems: development and first validation of scales. In: Environment \& Behavior 39/6: 754-778.

Hurst, M./Dittmar, H./Bond, R./Kasser, T. (2013): The relationship between materialistic values and environmental attitudes and behaviors: A meta-analysis. In: Journal of Environmental Psychology 36: 257-269.

Johnstone, M.-L./Tan, L. P. (2015): Exploring the Gap Between Consumers' Green Rhetoric and Purchasing Behaviour. In: Journal of Business Ethics 132/2: $311-328$

Kaiser, F. G./Byrka, K./Hartig, T. (2010): Reviving Campbell's Paradigm for Attitude Research. In: Personality and Social Psychology Review 14/4: 351-367.

Lavergne, K. J./Pelletier, L. G. (2015): Predicting individual differences in the choice of strategy to compensate for attitude-behaviour inconsistencies in the environmental domain. In: Journal of Environmental Psychology 44: 135-148.

O'Rourke, D./Lollo, N. (2015): Transforming Consumption: From Decoupling, to Behavior Change, to System Changes for Sustainable Consumption. In: Gadgil, A./Tomich T.P. (ed.): Annual Review of Environment and Resources 40. Palo Alto, CA: 233-259.

Rabinovich, A./Webley, P. (2007): Filling the gap between planning and doing: Psychological factors involved in the successful implementation of saving intention. In: Journal of Economic Psychology 28/4: 444-461.

Stich, A./Wagner, T. (2012): Fooling Yourself: The Role of Internal Defense Mechanisms in Unsustainable Consumption Behavior. Advances in Consumer Research 40: 408-416.

\section{Acknowledgement}

This project was funded by The European Commission, Research Programme FP 7. The author thanks Ambra Brizi, Fridanna Maricchiolo, Anke Fischer, Mirijam Mock, Vlad Pandur, Wouter Spekkink, and Alberto Diaz for data collection and analysis in the Italian, Scottish, Austrian, Romanian, Dutch, and Spanish case studies.

\section{AUTHOR + CONTACT}

Ines Thronicker is an environmental psychologist at the Helmholtz Centre for Environmental Research UFZ. Her research mainly focuses on environmentally relevant behaviour, behaviour change, and evaluation of intervention studies.

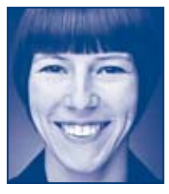

Helmholtz Centre for Environmental Research - UFZ, Permoserstr. 15, 04318 Leipzig, Germany. Email: ines.thronicker@ufz.de
MANAGEMENT UND WIRTSCHAFT PRAXIS

\section{Verantwortung} managen

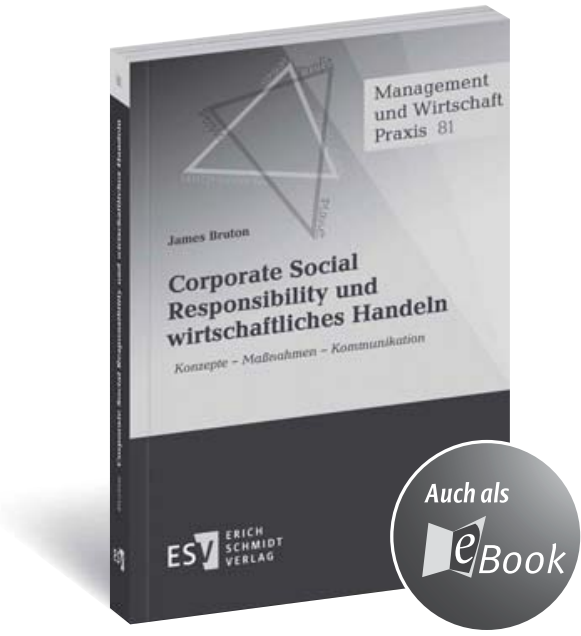

\section{Corporate Social Responsibility und wirtschaftliches Handeln} Konzepte-Maßnahmen - Kommunikation

Von Prof. Dr. James Bruton

2016, VIII, 248 Seiten, mit zahlreichen Abbildungen und Tabellen, $€$ (D) 34,95, ISBN 978-3-503-16622-0 Management und Wirtschaft Praxis, Band 81

Einen systematischen Zugang zu den wichtigsten Funktionen und Handlungsfeldern von CSR entwickelt James Bruton: Vom konzeptionellen Rahmen, Zielen und Strategien bis zur Planung und Implementierung von CSR-Maßnahmen - von CSR-Controlling als einem Instrument zielgerichteter Maßnahmenbewertung zu CSR-Kommunikation und Berichterstattung. Ein prägnanter, gut verständlicher Einstieg mit vielen Fallbeispielen und Übersichten.

Weitere Informationen:

Dwww.ESV.info/16622

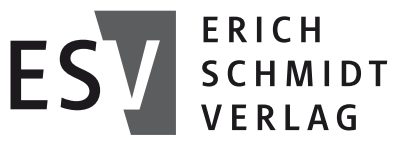

\section{Auf Wissen vertrauen}

Erich Schmidt Verlag GmbH \& Co. KG · Genthiner Str. $30 \mathrm{G} \cdot 10785$ Berlin Tel. (030) 2500 85-265 · Fax (030) 2500 85-275 ·ESV@ESVmedien.de·www.ESV.info 